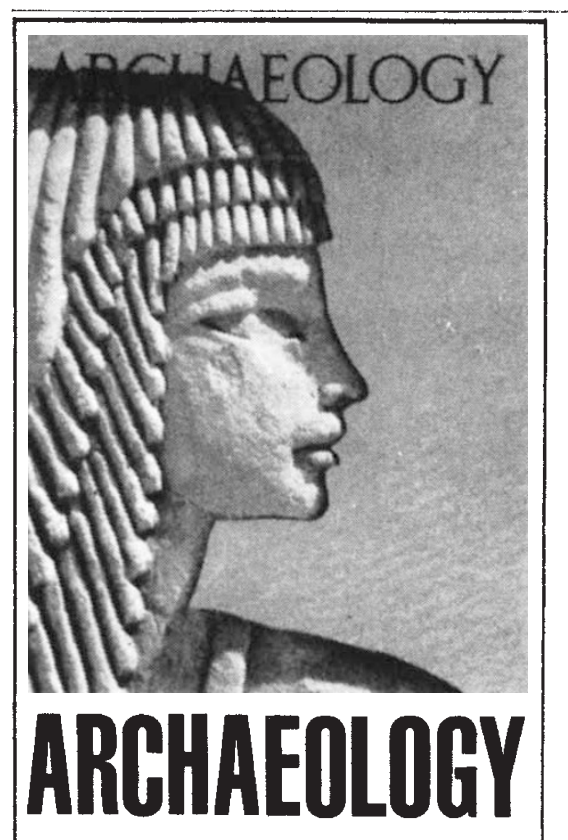

\section{The Magazine for Past Lovers}

Admit it - you've always been secretly fascinated by the mysteries of antiquity... always wondered what life was really like in ancient Egypt, China, Greece, Mexico, Peru. Find out in ARCHAEOLOGY Magazine! Six times a year its authoritative clearly-written articles and stunning color photographs bring the ancient world alive. Meet the peoples of the past. Marvel at their achievements, and admire the beauty they left behind. There's nothing else like ARCHAEOLOGY. Try it now.

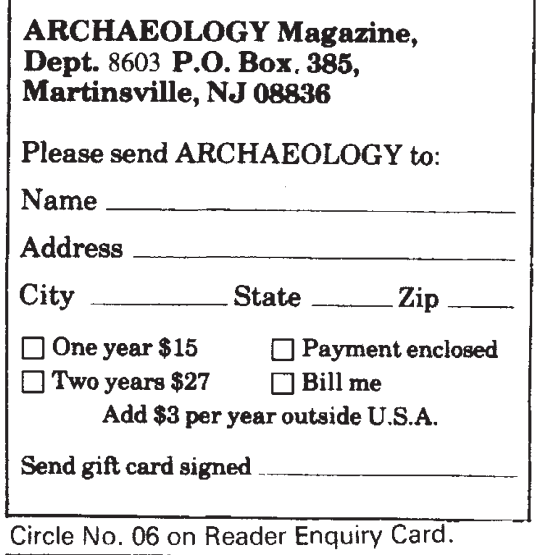

superbly interesting characters appear and the material is handled in a masterly fashion.

The first section recounts the social and historical backgrounds, the second contains accounts of Linnaeus, Cuvier, Audubon, Rafinesque, Swainson and Charles Kingsley. Later sections feature Waterton, Gosse, Ward, Mary Anning, the Bucklands, Owen, Sedgewick, Murchison, Huxley and Darwin. But the treatment is not merely biographical; rather, the work and the influence of these "giants" of the nineteenth century is skilfully woven into an account of the development of British natural history, although biographical details have been included to set them in their background. In working this complicated tapestry into an attractively presented, enjoyable and well-written story Lynn Barber deserves all credit.

No doubt it is because of her background as an experienced journalist and broadcaster that her book is presented with such panache. This background may, however, have led her to include some "human interest" stories which are generally now discredited amongst historians of natural history. Thus, the loss of labels from Cuming's mollusc shell collection due to Mrs Gray's carelessness is now dismissed as a canard. Nor was the unfortunate A.W.E. O'Shaughnessy's appointment in the British Museum to work on insects due solely to the influence of his patron as is inferred here; he was simply transferred from one department within the Museum to another, having passed a test of his knowledge of zoology which the other contender had failed.

One has to say that most of the sources used by Miss Barber are secondary. I doubt whether one can rely overmuch on Kingsley's view of Victorian natural history, or on William Swainson and especially not on Audubon for objective

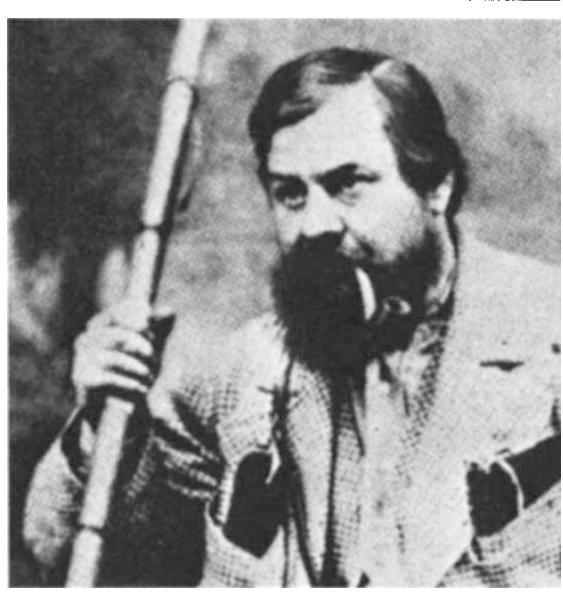

Frank Buckland, naturalist extraordinary

views of their contemporaries. They were all too involved in the period themselves, and Swainson and Audubon certainly had axes of various kinds to grind. The reliance on secondary sources tends to affect the overall images in the book, and also possibly accounts for some of the more alarming generalizations and particular errors. Surely it is not true that between Cuvier's Le Règne Animal of 1817 and Darwin's Origin of Species in 1859 " almost no major breakthroughs were made'? Two discoveries alone, that of Schwann (1839) of animal cells, and that of the mammalian ovum by von Baer (1827), would today be given the accolade of "breakthroughs",

For these and other reasons Lynn Barber's book cannot be credited as an original history of natural history, but as a readable and well-produced introduction to the subject it is unsurpassed.

Alwyne Wheeler is editor of the Archives of Natural History (formerly the Journal of the Society for the Bibliography of Natural History) and works at the British Museum (Natural History).

\title{
The "why" of animal culture
}

\section{W.C. McGrew}

The Evolution of Culture in Animals. By John Tyler Bonner. Pp.216. (Princeton University Press: 1980 .) £8.10, \$14.50.

A Distinguished cell biologist, J.T. Bonner, has written an ambitious book on the behaviour of animals. In it, he tackles the question of culture as a direct product of the evolutionary processes of natural selection: "[Culture] . . . is as biological as any other function of the organism, for instance, respiration or locomotion". In addressing social scientists, Bonner does not shrink from the implications of this position for human culture and confronts the issues in his opening chapter. From the beginning it is a pleasure to find a book so lucidly written and so free of jargon.

The author's ultimate goal is to explain why we (humans) have culture at all. To appreciate its adaptive significance requires a step-wise reconstruction of its phylogeny, and it is to this task that much of the book is directed. Bonner starts at the most basic levels of evolutionary mechanisms and advances on a broad front. His definitions are as comprehensive as possible; culture is defined as ". . . the transfer of information by behavioural means, most particularly by the process of teaching and learning'. (Such a definition is not without faults, for instance it gives no inkling of the cumulative nature of the phenomenon). The author compares the genome and the brain as informationprocessing structures, with genes and "memes", respectively, as the units of information transmission - here, and elsewhere in the book, he calls upon Dawkins's The Selfish Gene. The latter 
system is speedier and more flexible, but it is ultimately limited by the former. The emergence of large brains in human evolution is credited to neoteny, that is, the retention of juvenile traits whereby the brain goes on growing in size after the growth of the rest of the body has slowed or ceased.

Having laid the structural groundwork, Bonner turns to the most basic behaviours. A long chapter on animal societies (which draws heavily on Wilson's Sociobiology) relies on the premise that culture requires communication, which is most developed in social organisms. Here, and throughout the book, Bonner chooses to start with microorganisms and work his way through progressively more complex multicellular forms. An excellent discussion of genetic flexibility is followed by the introduction of the concept of a dichotomy of behavioural flexibility: single-response behaviour versus multiple-choice behaviour; this appears to be "nature versus nurture" re-labelled.

The real problems begin to arise with the author's treatment of learning and teaching. All social learning seems to be classified as imitation, with no distinction being made between types requiring differing degrees of mental ability mynah birds and human infants may both learn English, but the learning of the bird is merely mindless mimicry. No mention is made of "mixed" forms, for example observational learning by a combination of stimulus enhancement (social) and trialand-error learning (non-social). Finally, there is no reference to behaviours which involve communication but not (necessarily) learning, social facilitation of pecking in domestic chicks, for example. Crucial to the author's argument is teaching, which he defines as "... the release of sets of signals specifically designed to alter the behaviour of another individual"'. This presents a rare example of ambiguity: in a general sense such a definition applies to all communication; in a more specific sense, it leaves open the question of whether or not intentionality (or goal-directedness) is involved. The reader is told that a large share of teaching by higher vertebrates can be considered as parental guidance, and that a parent will shape its offspring's imitative performance with nudges, pokes and slaps. But, apart from a single anecdote, no evidence of this sort of behaviour is presented. Contrary to the author's conclusion, it seems likely that it is just this sort of teaching which is conspicuously absent in non-human animals.

The book builds toward a synthetic final chapter which I found somewhat bewildering. Norton-Griffiths's exemplary work on the intergenerational transmission of feeding techniques in oyster-catchers is given suitable credit, but a number of other, equally significant studies are not mentioned. The "natural experimental" research into cultural innovation and diffusion in Japanese monkeys rates only one paragraph; an admittedly fascinating anecdote of one-trial, avoidance learning by elephants is given preference to the many studies of culture in non-human primates - Menzel's volume on the subject is ignored; fidelity to nesting sites in migratory birds is emphasized, in spite of the fact that no social learning need be posited, just as it is not invoked to explain the homing of Pacific salmon to spawn; even the memorable example of milkbottle opening by tits merits only three sentences. Finally, the section on human culture cites no specific examples, and some of its general conclusions will cause disquiet amongst the social scientist for whom the book is intended; for example, the author's linking of the rise of culture to the rise of writing seemingly bars extant pre-literate societies from consideration.

Yet, overall, in this book Bonner has produced a clear, compelling and wideranging account of the bases for social communication in animals. However, those more interested in the evolutionary mechanisms of transition from non-human to human culture are left wanting. That particular book remains to be written.

W.C. McGrew is a Lecturer in Psychology at the University of Stirling and a Visiting Faculty Member at the University of North Carolina at Charlotte.

His publishers describe him as "a passionate observer of nature", and this is what emerges from his prose. He gives us accurate and percipient accounts of the plants, insects, mammals and particularly the birds seen in his garden and in the Hampshire countryside. Some scientists may find his description of his feelings, and his attribution of human emotions to birds and even insects, alien to their tastes, but they will soon be brought back to earth by his unsentimental and accurate accounts of life and death in the countryside.

Hudson's love of rural life was mirrored by his hatred for urban living. He disliked

\section{SCIENTIFIC BOOKSHOP}

H.K. LEWIS can supply works in all branches of Pure and Applied Science. Catalogues on request. Please state interests.

\section{SCIENTIFIC LENDING LIBRARY}

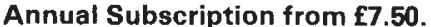

(Available in U.K. only)

Reduced rates for multiple subscriptions.

\section{Prospectus post free on request.}

Quarterly List of New Books and new editions added to the Library sent post free to subscribers regularly.

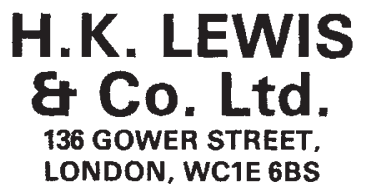

Telephone: 01-387 4282

Telegrams: "Publicavit,

London, WCIE 6BS."

Circle No. 23 on Reader Enquiry Card.

the townsmen, with "their pale civilized faces - they are out of my world - the real world". His passion was for "wildness the rude heath, the beautiful desolation; furze and ling and bramble and bracken to grow on me, and only wild creatures for visitors and company". He was of course aware that he was observing not the natural face of England, but the result of the interplay of human activities and ecological processes. He describes prehistoric barrows as well as traditional farmhouse and agricultural activities. But at the time he was writing it was possible to imagine that there was a harmony between man and nature which resulted in the beautiful landscape he so vividly describes.

How he would have hated the changes which have taken place in his beloved Hampshire in recent years. Many of the woods and heaths have gone, some of the hedges have been ripped out. Men are even prospecting for oil! Modern farming is very different from that of his day. Yet a great deal remains. We can, if we are lucky, still see most of the sights he so graphically describes. But few of us have his "seeing eye", and in a lifetime of study may not make all the observations his skill and his sympathy made possible in a few brief years at the beginning of this century.

Kenneth Mellanby is an editor of Collins' New Naturalist series, which is concerned with wildlife in Britain. His Farming and Wildlife, in this series, will appear in 1981. was, in South America or rural England. 